\title{
Meatal stenosis following circumcision with Plastibell device and conventional dissection Surgery; a prospective investigation
}

\author{
Kamran Ghods ${ }^{1}$, Setareh Soltany ${ }^{2}$, Jafar Alavy Toussy ${ }^{2}$, Raheb Ghorbani ${ }^{3}$, Davood Arab ${ }^{1}$, Arash Ardestani-Zadeh ${ }^{1}$, \\ Hamidreza Hemmati ${ }^{1}$
}

${ }^{1}$ Clinical Research Development Unit, Kowsar Hospital, Semnan University of Medical Sciences, Semnan, Iran

${ }^{2}$ Cancer Research Center, Semnan University of Medical Sciences, Semnan, Iran

${ }^{3}$ Social Determinants of Health Research Center, Semnan University of Medical Sciences, Semnan, Iran

\section{A R T I C L E I N F O}

Article Type:

Original

\section{Article History:}

Received: 10 May 2017

Accepted: 14 August 2017

ePublished: 20 September 2017

\section{Keywords:}

Circumcision

Meatal stenosis

Conventional dissection surgery

Plastibell device

\begin{abstract}
A B S T R A C T
Introduction: Meatal stenosis is a late complication of circumcision.

Objectives: This study was designed to determine its prevalence, its relationship with age of circumcision and its applied method.

Material and Methods: This prospective study was conducted between December 2006 and January 2012. A total of 2389 boys, equal to or less than 6 years were circumcised using the Plastibell device (PD) or conventional dissection surgery (CDS). They followed up 12 months after surgery. Signs and symptoms of meatal stenosis recorded and the meatus evaluated for stenosis.

Results: Meatal stenosis was diagnosed in 41 boys (1.7\%). Twenty-five of patients were asymptomatic (61\%). The difference between the mean age of circumcision in patients with meatal stenosis and the others were statistically significant. In newborns the prevalence of meatal stenosis was more than the other ages (15\% versus $1.4 \%, P<0.01)$. Concerning the method of circumcision, a significant difference on the prevalence of meatal stenosis was detected too $(0.8 \%$ in PD versus $3.6 \%$ in CDS; $P<0.001)$. The mean interval between circumcision and diagnosis of meatal stenosis was 9.59 months.

Conclusion: Symptomatic presentation of meatal stenosis may be late and it needs long-term follow-up. Its prevalence is higher in younger boys. Thus, circumcision in younger boys, especially in neonates is not recommended. Using PD has lower rate of meatal stenosis in comparison to CDS. Hence, the result of this study showed, the PD is preferable in younger boys.
\end{abstract}

Implication for health policy/practice/research/medical education:

The study emphasizes the superiority of the Plastibell device in circumcision, because of its simplicity and lower complication risk.

Please cite this paper as: Ghods K, Soltany S, Alavy Toussy J, Ghorbani R, Arab D, Ardestani-Zadeh A, Hemmati H. Meatal stenosis following circumcision with Plastibell device and conventional dissection Surgery; a prospective investigation. J Renal Inj Prev. 2018;7(2):84-88. DOI: 10.15171/jrip.2018.20.

\section{Introduction}

Circumcision the oldest and most prevalent surgical procedures in boys, is performed throughout the world for ritual, traditional or medical reasons (1). Currently, one-sixth of world's male population approximately is circumcised (2). Comparable to all surgicaql procedures, circumcision have various complications. These adverse complications are categorized as early and late complications (3). One of the late complications is meatal stenosis (4) which is possibly due to of ligation of the frenular artery or from ammoniacal meatitis. It accounts for $26 \%$ of the late complications (5). Complication rates depend on various factors such as anatomic abnormalities, medical comorbidities, surgical techniques, and the age of circumcision (5).

Numerous studies have been published concerning 
post-circumcision meatal stenosis in different ages with inconsistent results (2,6-8). In addition, studies regarding the role of circumcision methods in meatal stenosis are scarce.

\section{Objectives}

We designed this study to evaluate the cases of meatal stenosis demonstrating its prevalence and its relation to the age of the child at the time of circumcision and the used method. Various procedures are used for circumcision. Conventional dissection surgery (CDS) and circumcision with the Plastibell device (PD) are two methods most commonly used (9) that compared in this study.

\section{Patients and Methods}

This prospective study was conducted in Semnan University of Medical Sciences. Study was conducted on 2526 boys aged 6 years or less, who were circumcised in an outpatient clinic between December 2006 to January 2012. The participants had not any history of urological anomaly. All of the procedures were done by a single surgeon.

Participants were circumcised by one of the two methods; the Plastibell method or CDS. We explained both methods to the parents and they chose the technique for their child. If they could not decide, we conducted circumcision with Plastibell in age less than 2 years and conventional method was conducted for age more than 2 years. Hence, the proportion of subjects in Plastibell method was more than that of conventional group.

All surgeries were performed under local anesthesia with penile ring block. In Plastibell technique, an initial dorsal slit was needed to allow the protective bell to be placed. Then foreskin was pulled up and an appropriately sized Plastibell placed over the glans and under the foreskin. A non-absorbable string was tightly tied around the device and the prepuce distally to it was excised. The bell would eventually fall off, after necrosis within few days.

In dissection technique, two circumferential incisions were made, one at the shaft skin around the coronal sulcus, and the other one at the mucosa just proximal to the coronal sulcus. Then the foreskin between the two incisions was excised and the wound was closed with a 0.4 plain catgut. Acetaminophen was used as an analgesic and no dressing was applied in both methods. Boys should undergo a sitz bath with water twice a day and gentamicin ophthalmic ointment was administered to use on the operative site for ten days. The boys were followed up and evaluated one week, then 3, 6 and 12 months after surgery for meatal stenosis. The criteria for diagnosis of meatal stenosis were based on the distortion of meatus from an ellipsoid to a pinpoint shape, and also inability to pass a $5 \mathrm{~F}$ lubricated feeding tube below age one year and $8 \mathrm{~F}$ feeding tube between 1-6 years (10).

\section{Ethical issues}

1) The research followed the tenets of the Declaration of Helsinki; 2) informed consent was obtained from the parents of children; and 3) This study was approved by the Ethics Committee of Semnan University of Medical Sciences, Semnan, Iran (\#90/12751).

\section{Statistical analysis}

Data were analyzed by SPSS 22 (IBM SPSS Inc.). We used $t$ test for comparing mean of quantitative variables and chi-square test (or Fisher's exact test when necessary) for evaluating association between qualitative ones. In all statistical tests, $P<0.05$ was considered as significant.

\section{Results}

Of 2526 boys, 137 participants did not return for following up. Thus we worked on 2389 boys. According to the Table 1 , the mean age of the children was 22.79 months (range 12 days to 6 years). Sixty cases were neonates (2.5\%). The circumcision was conducted on $66.5 \%$ of cases with PD and in the others through CDS. Mean age in the Plastibell group was 9.27 months and in the conventional group was 49.60 months $(P<0.001)$.

Meatal stenosis was diagnosed in 41 boys (1.7\%). Twenty-five of the patients were asymptomatic (61\%). In symptomatic patients, the most common symptom was discomfort on voiding (pain, crying or burning) or dysuria. Decreased urinary caliber, urinary deviation and blood on meatus were the other symptoms was noted by the parents. Five patients $(12.2 \%)$ had more than one symptom.

There was a correlation between age of circumcision and meatal stenosis (Table 2). The difference between the mean age of circumcision in the patients with meatal stenosis (12.88 months) and the other children (22.96 months) was statistically significant $(P=0.003)$. In addition, in neonates, the prevalence of meatal stenosis was more than the other ages $(15 \%$ versus $1.4 \%, P<0.01)$.

Table 1. Demographic characteristics of the subjects

\begin{tabular}{ll}
\hline Variable & Value \\
\hline Circumcision with PD (\%) & 66.5 \\
Mean age (months) & 22.79 \\
Neonates (\%) & 2.5 \\
Prevalence of stenosis (\%) & 1.7 \\
Mean interval between circumcision and diagnosis (months) & 9.59 \\
\hline
\end{tabular}

Table 2. Relationship of stenosis and age of circumcision

\begin{tabular}{llll}
\hline & With stenosis & Without stenosis & $\boldsymbol{P}$ value \\
\hline Mean age (months) & 12.88 & 22.96 & 0.003 \\
Neonates (\%) & 15 & 85 & $<0.01$ \\
Non-neonates (\%) & 1.4 & 98.6 & $<0.01$ \\
\hline
\end{tabular}


With regard to the method of circumcision, we found a significant difference on the prevalence of meatal stenosis between two methods $(0.8 \%$ in $\mathrm{PD}$ and $3.6 \%$ in CDS, $P<0.001$ ) (Table 3). The mean interval between circumcision and diagnosis of meatal stenosis was 9.59 months. This interval was not significantly different between two methods (10.50 months in PD versus 9.21 months in CDS, $P>0.05)$.

\section{Discussion}

Meatal stenosis is an abnormal narrowing of the urethral meatus in men and is most commonly associated with circumcision (11). Studies have found meatal ulcerations in $8 \%$ to $31 \%$ of circumcised boys. Traumatic meatitis of the unprotected post circumcision urethral meatus and/ or meatal ischemia following damage to the frenular artery at circumcision may lead to meatal stenosis (7). The prevalence of meatal stenosis following circumcision is unknown (12). It is reported to be the commonest complication of circumcision. On the other hand some major series analyzing the result of circumcision have even failed to recognize, meatal stenosis as a possible complication (8). In some reports, its range is between $2.9 \%$ to $11.1 \%$ (7). In the present study on 2389 circumcised children, meatal stenosis was diagnosed in 41 boys (1.7\%). The wide variation in frequencies of adverse effect following circumcision is likely due to several factors such as age at circumcision, training and expertise of the provider (13). Higher rates of meatal stenosis may be seen in areas in which the procedure is done by nonqualified regional people $(11,14)$. In our study all the procedures were conducted by an expert surgeon. It may be one of the major reasons for the low rate of meatal stenosis.

Furthermore, there is a variation in methodological issues such as duration of follow-up that can affect the estimated frequency of complications (13). Meatal stenosis is often missed because boys do not get long-term follow-up care after circumcision. Its symptoms often are mistaken for urinary tract infections and may be treated empirically by antibiotics (15). The symptoms of meatal stenosis are usually ignored for many months until parents detect the child's voiding habit (8).

We followed-up the patients 12 months after surgery for meatal stenosis. Twenty-five of the patients were asymptomatic (61\%). In symptomatic patients, the most common symptom was dysuria. The mean interval between circumcision and diagnosis of meatal stenosis was 9.59 months. In the study by Persad et al, conducted on 12 cases of meatal stenosis following circumcision, the main symptoms were penile pain at the initiation of micturition, in 12 of 12 patients (8). In another study by Cartwright et al, dysuria was the most common symptom (16), which was consistent with our results. Furthermore Upadhyay et al detected that in $32 \%$ of their patients, the diagnosis of meatal stenosis were made incidentally. We
Table 3. Relationship of stenosis and circumcision method

\begin{tabular}{llll}
\hline & CDS & PD & $P$ value \\
\hline $\begin{array}{l}\text { Prevalence of stenosis (\%) } \\
\begin{array}{l}\text { Mean interval between circumcision } \\
\text { and diagnosis (months) }\end{array}\end{array}$ & 3.6 & 0.8 & $<0.001$ \\
\hline
\end{tabular}

have the higher rate of asymptomatic patients (61\%). Also, the median age at presentation of symptomatic children was 48 months (range 3 months to 13 years) following circumcision in the study by Upadhyay et al (17), while in our study it was 9.59 months. We only followed the patients for 1 year but they followed up it for 12 years. It can be concluded that symptomatic presentation of meatal stenosis after circumcision can be very late and it needs long-term follow-up.

In our study, the age of circumcision was related to the incidence of meatal stenosis. The frequency of meatal stenosis was higher in younger boys, especially it was more considerable in neonatal period $(15 \%$ in neonates versus $1.4 \%$ in other ages). This is in line with the study of Ceylan et al, which detected that meatal stenosis is more common in newborn circumcision (18). Machmouchi and Alkhotani compared the outcome of circumcisions conducted in early neonatal period and at 5 months age. Complications including meatal deformities, meatal stenosis, adhesions and infection were more frequent and more significant in the neonatal circumcision group (6). Van Howe found that neonatal circumcision increases the risk of penile inflammation particularly in boys younger than three years old (19). Accordingly in another study, the diagnosis of meatal stenosis was made in 24 of 329 circumcised boys. All of the boys with meatal stenosis were circumcised neonatally. Nearly all individuals required meatotomy to resolve their symptoms. The study concluded that meatal stenosis may be the most common complication following neonatal circumcision. They emphasized that the frequency of this complication and the need for surgical correction should be disclosed as part of the informed consent for neonatal circumcision (20). Hence, according to these studies and the results of the present study, it is better not to conduct circumcision in younger boys, especially in neonatal period.

Our study showed that using PD has lower rate of meatal stenosis in comparison to CDS $(0.8 \%$ versus $3.6 \%)$. A recent study highlighted that different types of circumcision result in different degrees of meatal stenosis stating that the Plastibell results in more incidence of narrowed meatus (21). While in some other studies, the relation of circumcision methods and meatal stenosis are similar to our findings. As an example, in a study from Nigeria on 141 circumcised boys, the most common complications were minor including bleeding (9\%) and meatal stenosis (3.5\%). Complications were substantially more common when circumcision had been performed freehand rather than using the PD (22). Sörensen and 
Sörensen recorded the late morbidity and complications in 43 patients circumcised with the PD during the mean observation period of 29 months. No serious complications were encountered. They detected, the Plastibell method leaves a varying amount of foreskin intact in comparison to classical dissection techniques. This could explain why meatal ulcers/stenosis are not seen when employing this method (23). In a study on 119 boys circumcised with the PD with a follow up of 120 days after surgery, only one patient had meatal stenosis while using diaper (24). Thus the result of above mentioned studies is consistent with the finding of our study regarding use of PD in comparison to CDS.

In addition, according to Clavien classification of surgical complications (25) this study can be classified as grade IIIb of surgical or procedure-related complications.

\section{Conclusion}

To conclude, symptomatic presentation of meatal stenosis after circumcision may be very late and it needs long-term follow-up. Its prevalence is related to the age of the child, and is higher in younger boys. Thus, circumcision in younger boys, especially in neonates is not recommended. Using PD has lower rate of meatal stenosis in comparison to CDS. Hence PD is preferable in younger boys.

\section{Limitations of the study}

This study was conducted on a limited proportion of patients and we suggest larger studies on this feature of circumcised individuals.

\section{Acknowledgments}

We would like to thank the Clinical Research Development Unit of Kowsar Educational and Research and Therapeutic Center of Semnan University of Medical Sciences for providing facilities to this work.

\section{Authors' contribution}

SS, KG, DA, AA and $\mathrm{HH}$ conceived the study and performed the experiments. JATand RG contributed to methodology and analyzed the data. All authors read, revised, and approved the final manuscript.

\section{Conflicts of interest}

There were no points of conflicts.

\section{Ethical considerations}

Ethical issues (including plagiarism, data fabrication, double publication) have been completely observed by the authors.

\section{Funding/Support}

This project supervised by research deputy Semnan University of Medical Sciences without any Grant (proposal number\# 874).

\section{References}

1. Özdemir E. Significantly increased complication risks with mass circumcisions. Br J Urol 1997;80:136-9.

2. Yegane RA, Kheirollahi AR, Salehi NA, Bashashati M, Khoshdel JA, Ahmadi M. Late complications of circumcision in Iran. Pediatr Surg Int. 2006;22:442-5. doi: 10.1007/s00383-006-1672-1.

3. Pieretti RV, Goldstein AM, Pieretti-Vanmarcke R. Late complications of newborn circumcision: a common and avoidable problem. Pediatr Surg Int. 2010;26:515-8. doi: 10.1007/s00383-010-2566-9.

4. Mondal SK, Ali MA, Alam MK, Hasina K, Talukder AR, Yusuf MA, et al. Use of lubricant at meatus and circumcision site in younger children prevent post circumcision meatal stenosis: a randomized control trial. J Shaheed Suhrawardy Med Coll. 2013;5:35-38. doi: 10.3329/jssmc.v5i1.16204.

5. Krill AJ, Palmer LS, Palmer JS. Complications of circumcision. Sci World J 2011;11:2458-68. doi: $10.1100 / 2011 / 373829$.

6. Machmouchi M, Alkhotani A. Is neonatal circumcision judicious? Eur J Pediatr Surg. 2007;17:266-9. doi: 10.1055/ s-2007-965417.

7. Van Howe RS. A Cost-utility analysis of neonatal circumcision. Med Decis Making. 2004;24:584-601. doi: 10.1177/0272989X04271039.

8. Persad R, Sharma S, McTavish J, Imber C, Mouriquand PD. Clinical presentation and pathophysiology of meatal stenosis following circumcision. Br J Urol. 1995;75:91-3.

9. Mousavi SA, Salehifar E. Circumcision complications associated with the plastibell device and conventional dissection surgery. A trial of 586 infants of ages up to 12 months. Adv Urol. 2008:606123. doi: 10.1155/2008/606123.

10. Litvak AS, Morris JA, McRoberts JW. Normal size of the urethral meatus in boys. J Urol 1976;115:736-7.

11. Bazmamoun H, Ghorbanpour M, Mousavi-Bahar SH. Lubrication of circumcision site for prevention of meatal stenosis in children younger than 2 years old. Urol J 2008;5:233-6.

12. Mahmoudi H. Evaluation of meatal stenosis following neonatal circumcision. Urol J. 2005;2:86-88.

13. Weiss HA, Larke N, Halperin D, Schenker I. Complications of circumcision in male neonates,infants and children: a systematic review. BMC Urol. 2010;10:1-13. doi: 10.1186/1471-2490-10-2.

14. Berry CD Jr, Cross RR Jr. Urethral meatal caliber in circumcised and uncircumcised males. AMA J Dis Child. 1956; 92:152-6. doi: 10.1001/archpedi.1956.02060030146007

15. Meatal Stenosis. Medscape wensite. http://emedicine. medscape.com/article/1016016-overview. Updated Sep 2016.

16. Cartwright PC, Snow BW, McNees DC. Urethral meatotomy in the office using topical EMLA cream for anesthesia. J Urol. 1996;156:857-8.

17. Upadhyay V, Hammodat HM, Pease PW. Post circumcision meatal stenosis: 12 years' experience. $\mathrm{N}$ Z Med J. 1998;111:57-8.

18. Ceylan K, Burhan K, Yilmaz Y, Can S, Kus A, Mustafa G. Severe complications of circumcision: an analysis of 48 cases. J Pediatr Urol 2007;3:32-5. doi: 10.1016/j. jpurol.2006.02.009. 
19. Van Howe RS. Neonatal circumcision and penile inflammation in young boys. Clin Pediatr (Phila). 2007;46:329-33. doi: 10.1177/0009922806295708.

20. Van Howe RS. Incidence of meatal stenosis following neonatal circumcision in a primary care setting. Clin Pediatr. 2006;45:49-54. doi: 10.1177/000992280604500108

21. Graves J. Pinpoint meatus: iatrogenic? Pediatrics. 1968 41:1013.

22. Osuigwe A, Ikechebelu J, Okafor P. Circumcision-related complications in the male: experience amongst the Igbo's of Southeast Nigeria. Afr J Urol. 2004;10:246-251.

23. Sörensen SM, Sörensen MR. Circumcision with the
Plastibell device, a long term follow-up. Int Urol Nephrol 1988;20:159-166.

24. Bastos Netto JM, Gonçalves de Araújo J Jr, Noronha MF, Passos BR, Lopes HE. A prospective evaluation of

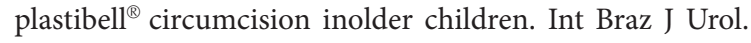
2013;39: 558-64. doi: 10.1590/S1677-5538.IBJU.2013.04.14.

25. Dindo D, Demartines N, Clavien PA. Classification of surgical complications: a new proposal with evaluation in a cohort of 6336 patients and results of a survey. Ann Surg 2004;240:205-13. doi: 10.1097/01.sla.0000133083.54934.ae.

Copyright $\odot 2018$ The Author(s); Published by Published by Nickan Research Institute. This is an open-access article distributed under the terms of the Creative Commons Attribution License (http://creativecommons.org/licenses/by/4.0), which permits unrestricted use, distribution, and reproduction in any medium, provided the original work is properly cited. 